\title{
ENTRE PATRIOTAS Y POLIZONES \\ POLÉMICAS LETRADAS SOBRE LOS AMERICANOS \\ EN LA PRENSA PERIÓDICA (1810-1812)
}

\author{
BETWEEN PATRIOTS AND STOWAWAYS \\ LITERATE CONTROVERSIES ABOUT AMERICANS \\ IN THE PERIODICAL PRESS (1810-1812)
}

\author{
Mariana RosetTI \\ Universidad de Buenos Aires \\ Instituto de Literatura Hispanoamericana \\ Universidad Nacional de Quilmes \\ Centro de Historia Intelectual \\ marurosetti@gmail.com \\ ORCID: 0000-0003-0164-1224
}

\section{Resumen}

Las propuestas de la prensa hicieron uso en los años 1810-1812 del concepto de americanidad como una materia maleable desde la cual señalar injusticias y arbitrariedades. Para ello, los escritos públicos recurrieron a perspectivas en las que se construyeron aliados y enemigos y se utilizó el humor satírico como vía para suscitar la afinidad del lector. La flexibilidad del nombre americanos se utilizó como metáfora de la debilidad de autonomía política de las distintas provincias del continente americano. Nos interesa analizar al respecto algunas producciones de Juan López Cancelada que generaron respuestas vehementes del diputado de Tlaxcala en las Cortes de Cádiz, José María Guridi Alcocer, y de Servando Teresa de Mier. Estos tres pensadores hicieron uso de la prensa periódica para concretar o plantear soluciones políticas que los debates constitucionales erraban en contemplar o profundizar y lo hicieron recurriendo a los términos de patriotas y polizones.

Palabras clave: americanos; polémicas letradas; prensa periódica; Juan López Cancelada; José Miguel Guridi Alcocer; Servando Teresa de Mier

\begin{abstract}
During the years 1810-1812, the press proposals used the concept of Americanity as a malleable matter from which to point out injustices and arbitrariness. For this, public writings used perspectives in which allies and enemies were obtained and satirical humor was used to arouse the reader's affinity. The flexibility of the American name was used as a metaphor for the weakness of political autonomy of the different provinces of the American continent. We are interested in analyzing some productions of Juan López Cancelada in this regard that generated vehement responses from the deputy of Tlaxcala in the Cortes of Cádiz, José Miguel Guridi Alcocer, and by Servando Teresa de Mier. These three thinkers used the
\end{abstract}


periodical press to specify or propose political solutions that the constitutional debates erred in contemplating or deepening, and they did so by using the terms of patriots and stowaways.

Keywords: Americans; polemics of the men of letters; periodical press; Juan López Cancelada; José Miguel Guridi Alcocer; Servando Teresa de Mier.

\section{Información del artículo}

Recibido: 22 de agosto de 2019.

Aceptado: 5 de junio de 2020.

DOI: http://dx.doi.org/10.22201/iih.24486922e.2020.63.70428

\section{Introducción*}

En las representaciones e intervenciones públicas durante el periodo de 1808-1812 los americanos concibieron el debate político-constitucional como el ámbito propicio para configurar, defender y/o limitar las imbricaciones lingüísticas entre el vasallaje del Antiguo Régimen con el accionar ciudadano estipulado por la constitución gaditana en el año de 1812 actualizando de forma política las distintas quejas y reclamos jurídicos. En este periodo vertiginoso "vacío de representación", ${ }^{1}$ los letrados americanos utilizaron el discurso del reclamo jurídico criollista como prisma para construir una narrativa histórica de injusticias por parte de la corona española y luchar por la soberanía política. Observamos que las participaciones de los letrados americanos en la apertura de la opinión pública ampliaron el prisma criollista al dotar al reclamo de un basamento político-social integrando a los distintos sectores populares no contemplados en la Constitución gaditana (sobre todo castas y negros). En este periodo de debates

* Agradecemos la atenta lectura y las sugerencias del doctor Rodrigo Moreno sobre las vicisitudes del concepto de América-americanos durante el periodo independentista novohispano. A su vez, agradecemos las observaciones de los evaluadores del artículo que han sugerido lecturas muy enriquecedoras para el trabajo.

1 "[...] la declinación de la figura 'consensual' del Monarca supuso un vacío de representación que vulneró las formas de obediencia y negociación tradicionales ya que, si bien las minorías americanas se apresuraron a evitar caer en el vacío político, probablemente no lograron persuadir a la población de que la ausencia de la figura monárquica no implicaba una desaparición del arreglo político que la sustentaba." Antonio Ibarra, "Orden, desorden y atraso: el acertijo latinoamericano de la originaria inestabilidad política y el tormentoso cambio institucional, a propósito del Bicentenario", Revista Uruguaya de Historia Económica, año 1, n. 1 (2011): 105. 
políticos y legales la americanidad fue considerada un locus de enunciación maleable y flexible, desde el cual denunciar fallas en el sistema colonial peninsular o evidenciar la unión inviable de sociedades sumamente heterogéneas dentro de un sistema político trasatlántico. Al respecto, nos interesan las observaciones de Carlos Herrejón Peredo sobre la utilización por parte de Miguel Hidalgo del término "América” a lo largo de sus discursos y escritos. Este historiador señala cómo el término fue usado por el líder insurgente de forma estratégica y teniendo en cuenta el peso de las palabras como armas de guerra: "Hidalgo se lanzó a la insurgencia no por la libertad de Nueva España ni de 'México', sino de 'América', declarando así su intención de lograr una realidad política diversa de la colonia y del centralismo [...] se dirige a los habitantes del virreinato llamándolos 'americanos' o "conciudadanos'". 2

Los conceptos de América/americanos nos convocan por tratarse de conceptos que, al igual que el de patria, fueron utilizados como nociones sumamente elásticas que trasladaron su significado desde un plano material-concreto (pertenencia a un territorio, geografía, clima y naturaleza) para pasar a designar una forma de ser particular tendiente a formar una legitimidad propia. ${ }^{3}$ En el periodo que trabajamos, esta particular forma de "ser americanos" fue concebida como la apropiación político-cultural y, sobre todo moral, de un locus de enunciación desde el cual muchos publicistas y

${ }^{2}$ Carlos Herrejón Peredo, "Hidalgo y la nación”, Relaciones, v. xxv, n. 99 (2004): 258.

${ }^{3}$ Guillermo Zermeño plantea el caso de la aparición del Diario de México (1805) como el primer cotidiano que habilitó la posibilidad de la creación del término "criollo-mexicano" y las vías comunicativas para que éste se exprese ("Apropiación del pasado, escritura de la historia y construcción de la nación en México”, en La nación y su historia. Independencias, relato historiográfico y debates sobre la nación: América Latina, siglo XIX, coord. de Guillermo Palacios, 81-112 (México: El Colegio de México, 2009), 132-133. Para ampliar el tema, sugerimos obras de Zermeño ("Los usos políticos de América/americanos (México 17501850)." Revista de Estudios Políticos, n. 134 (2006): 71-95, y “Apropiación del pasado”) como el artículo de Alfredo Ávila y Rodrigo Moreno ("El vértigo revolucionario. Nueva España 1808-1821", Nuevo Topo. Revista de historia y pensamiento crítico (Buenos Aires), n. 5 (2008): 99-125. Republicado en dossier: Lo revolucionario en las revoluciones de independencia iberoamericanas. Historia Política (coord. de Marcela Ternavasio), n. 4 (2010): 1-36. Consideramos esencial la observación que hace al respecto Herrejón Peredo sobre el discurso de Hidalgo: "Hidalgo se refiere al patriotismo como una virtud que va unida a la fidelidad y al amor a la nación. La dimensión local de la patria se abre y ubica en el horizonte universal [...] la patria, y consiguientemente la nación, por particular que sea, tiene derechos fundamentales que coinciden con los derechos del hombre" (Herrejón Peredo, "Hidalgo y la nación", 261). 
letrados plantearon fuertes críticas al sector opositor y pretendieron convencer a sus lectores o acólitos sobre los pasos a seguir actuando en consecuencia a este atributo. Sostenemos que ciertos letrados criollos (como fueron los casos de José Miguel Guridi Alcocer, Servando Teresa de Mier y Carlos María de Bustamante, entre otros) hicieron uso de este locus de enunciación para configurarse en guías del cambio político-social en su pasaje a una república todavía inexistente. Estos hombres de saber construyen sus argumentaciones y narraciones históricas desde un lugar crítico, es decir, articulan una mirada desplazada del vasallaje colonial y despliegan un patriotismo discursivo en el que organizan el pasado y estipulan pautas o pasos a seguir para sus lectores.

Estas nociones de patria y americanismo trabajadas de forma elástica por letrados criollos estuvieron en sintonía y diálogo con una retórica panhispánica frágil alentada por España desde 1808. En palabras del historiador Iriarte López, esta retórica panhispánica:

no llega a borrar completamente el lenguaje precedente, que distinguía sistemáticamente entre España y los territorios de Ultramar [...] El afán por reforzar los vínculos entre la península y América será simultáneo a la tentativa de incrementar el peso de la autoridad central sobre ésta [...] América, en definitiva, es subsumida en un plano retórico dentro de lo español, pero no resulta equiparada política ni administrativamente. ${ }^{4}$

Esta retórica nos convoca porque demuestra la "vulnerabilidad de las posesiones españolas en América”, como bien lo señala Alfredo Ávila en su estudio. ${ }^{5}$ Tanto Alfredo Ávila, por un lado, como Marco Antonio Landavazo, por otro, rescatan el plano retórico como espacio fundamental para analizar la implementación de la violencia del terror, así como también las diferentes estrategias y maniobras de acomodación que tanto realistas como insurgentes y, para nuestro caso letrados, hicieron en este periodo: “[E]ntre 1808 y 1824 ocurrió en México una verdadera revolución que no sólo marcó el final de la dependencia con España sino una transformación

${ }^{4}$ Ignacio Iriarte López, “América-España”, en Diccionario político y social del mundo iberoamericano, dir. de Javier Fernández Sebastián (Madrid: Fundación Carolina; Madrid: Sociedad Estatal de Conmemoraciones Culturales; Madrid: Centro de Estudios Políticos y Constitucionales, 2009), 122.

${ }^{5}$ Alfredo Ávila, En nombre de la nación. La formación del gobierno representativo en México (1808-1824) (México: Taurus, 2002), 48. 
radical en las prácticas y creencias que afectan las relaciones de poder en una sociedad". ${ }^{6}$

En relación con la transformación radical en las prácticas del periodo independentista novohispano, nos interesa retomar en este artículo la polémica que se produce en los años 1811 a 1812 entre Juan López Cancelada y Miguel Guridi Alcocer y de la cual participa lateralmente Servando Teresa de Mier desde su narrativa histórica. Esta polémica se llevó a cabo durante las sesiones extraordinarias de las Cortes de Cádiz y giró en torno a la representación política de los americanos. Este enfrentamiento verbal nos muestra que la política contestaria, ya preexistente en la esfera pública novohispana desde mediados del siglo XviII, ${ }^{7}$ adquiere en el periodo de guerras independentistas un rol protagónico principalmente en los periódicos que se sustentan en un tono polémico, combativo. Por otro lado, como lo desarrolla Verónica Zárate Toscano en varios de sus estudios, las posiciones de López Cancelada y de Guridi Alcocer eran irreconciliables. Sin

${ }^{6}$ Ávila, En nombre de la nación, 14. Al respecto, Landavazo sostiene: "ese discurso del terror tuvo una lógica interna [...] que exige ser desvelada. Partía de la premisa de que había responsables de los males que aquejaban al reino, a quienes había que identificar, y procedía entonces a su degradación moral para concluir después con la necesidad del exterminio de ese enemigo así identificado". Marco Antonio Landavazo, "Guerra, discurso y terror en la independencia de México", en Creación de estados de opinión en el proceso de independencia mexicano (1808-1823), coord. de Laura Suárez de la Torre, 99-124 (México: Instituto de Investigaciones Dr. José María Luis Mora, 2010), 100.

7 "La escasez de planteamientos y estudios sobre la esfera pública en la Nueva España dieciochesca puede deberse al éxito de algunas obras que subrayaron el 'surgimiento de la opinión pública' como un fenómeno asociado a la 'Modernidad' en los albores del siglo XIX." Gabriel Torres Puga, Opinión pública en Nueva España. Indicios de un silencio imposible (17671794) (México: El Colegio de México, 2010), 25. En diálogo con los aportes de Torres Puga, Iván Escamilla ha investigado sobre el aporte fundamental de la elite letrada eclesiástica novohispana "en el surgimiento de una esfera local de lo público y en la difusión de la modernidad ilustrada hacia la primera mitad del siglo xvin". Iván Escamilla, "La élite letrada eclesiástica y la cultura de la controversia, primera mitad del siglo xviı", en Expresiones y estrategias. La Iglesia en el orden social novohispano, coord. de María del Pilar Martínez López-Cano y Francisco Javier Cervantes Bello, 363-392 (México: Universidad Nacional Autónoma de México, Instituto de Investigaciones Históricas; Puebla: Benemérita Universidad Autónoma de Puebla, Instituto de Ciencias Sociales y Humanidades “Alfonso Vélez Pliego”, 2017), 365. Estas dos investigaciones cuestionan en parte la perspectiva tajante de François-Xavier Guerra, quien sostiene que la Modernidad como tal puede verse en Hispanoamérica en el periodo de 1808 a 1810, especialmente en respuesta y reacción, por un lado, a la Revolución Francesa, y por otro, a la vacancia del rey Fernando VII y la guerra independentista peninsular: "las nuevas formas de sociabilidad son ciertamente el lugar social en que se enraízan y el principal medio de difusión de la Modernidad”. François-Xavier Guerra, Modernidad e independencia: ensayos sobre las revoluciones hispánicas (Madrid: MAPFRE-América, 1992), 91. 
embargo, y en esto nos detenemos en este artículo, Zárate rescata cómo tanto uno como otro oponente buscaban lo mejor para los americanos, pero entendiendo a este grupo de forma diferenciada. ${ }^{8}$ En otras palabras, Cancelada rechazaba y criticaba al sector poderoso de los criollos por considerarlos nocivos para Nueva España y para el resto de los americanos, mientras que Guridi Alcocer apeló a la resignificación de los conceptos de patria y de americanidad desde argumentos jurídicos y legales para descalificar la labor periodística de Cancelada. El objetivo de Guridi Alcocer era específico: derribar cualquier vestigio de experiencia y observación de este escritor peninsular sobre las realidades americanas, en especial de la vida heterogénea y particular de Nueva España.

En nombre de los americanos: usos y polémicas

en la opinión pública

La apertura política promulgada por las Cortes de Cádiz estipuló la igualdad política que repercutió tanto en el ámbito jurídico como en el ámbito público al sancionar el 10 noviembre de 1810 el decreto de libertad política de la imprenta. Este decreto contempló: “[...] la facultad individual de los ciudadanos de publicar sus pensamientos e ideas políticas es, no sólo un freno de la arbitrariedad de los que gobiernan, sino también un medio de ilustrar a la Nación en general, y el único camino para llevar al conocimiento de la verdadera opinión pública". ${ }^{9}$ La capacidad, la diversidad y la divulgación de las publicaciones se concibieron en fenómenos tendientes a propiciar una verdadera opinión pública que salvaguardara el bienestar de la Nación española. Destacamos estos aspectos de instrumentación y defensa de la opinión pública ya que concibieron una pluralidad de voces, no obstante

${ }^{8}$ Véanse Verónica Zárate Toscano, "La cuestión americana en Juan López Cancelada”, en Insurgencia y republicanismo, coord. de Jesús Raúl Navarro García, 67-86 (Sevilla: Consejo Superior de Investigaciones Científicas, Escuela de Estudios Hispano-Americanos, 2006), 72, y de la misma autora "Con la pólvora en el tintero. Juan López Cancelada y la independencia novohispana", en Creación de estados de opinión en el proceso de independencia mexicano (1808-1823), coord. de Laura Suárez de la Torre, 195-228 (México: Instituto de Investigaciones Dr. José María Luis Mora, 2010), 224.

9 "Decreto IX, 10 de noviembre de 1810. Libertad política de la imprenta”, en Colección de los decretos y órdenes que han expedido las Cortes Generales y Extraordinarias desde su instalación en 24 de septiembre de 1810 hasta igual fecha de 1811 (Cádiz: Imprenta Real, 1811), 1:14. Énfasis nuestros. 
ceñidas a una forma unificada y moral, propias del Antiguo Régimen con miras a sostener una nación española de por sí sumamente controversial y problemática a esta altura de los acontecimientos. En palabras de Elías Palti:

[L]a ruptura del vínculo colonial trajo aparejadas [...] alteraciones políticas irreversibles. Privadas ya las nuevas autoridades de toda garantía trascendente, sólo la voluntad de los sujetos podía proveerles un fundamento de legitimidad, y ésta encarnaría en la "opinión pública". De allí que los gobernantes habrían de invocarla siempre. Tal invocación no sería, además, sólo retórica. En el curso del siglo xIX se difunde con rapidez la idea del "poder de la opinión". Ésta aparecerá como una suerte de tribunal en última instancia cuyo fallo será inapelable. ${ }^{10}$

Las propuestas de la prensa gaditana hicieron uso del concepto de americanidad como una materia maleable desde la cual señalar injusticias y arbitrariedades. Para ello, los escritos públicos recurrieron a perspectivas en las que se construyeron aliados y enemigos y se utilizó el humor satírico como vía para suscitar la afinidad del lector. La flexibilidad del nombre americanos se utilizó como metáfora de la debilidad de autonomía política de las distintas provincias del continente americano. Nos interesa analizar al respecto tres producciones de Juan López Cancelada (1765-1837?) que generaron respuestas vehementes por parte del diputado de Tlaxcala en las Cortes de Cádiz, José María Guridi Alcocer (1763-1828) y por parte de Servando Teresa de Mier (1763-1827). Estos tres pensadores hicieron uso de la prensa periódica para concretar o plantear soluciones políticas que los debates constitucionales gaditanos erraban en contemplar o profundizar. Para estos letrados, el problema americano - la incertidumbre sobre su representación políticadebía ser atendido prontamente. Sin embargo, esta urgencia y malestar no tuvo el impacto esperado en los diputados peninsulares de las Cortes de Cádiz y la polémica excedió las gradas del recinto para ocupar un lugar preponderante tanto en la prensa gaditana como en la prensa americana. ${ }^{11}$

${ }^{10}$ Elías Palti, El tiempo de la política. El siglo XIX reconsiderado (Buenos Aires: Siglo XXI Editores, 2007), 167.

${ }^{11}$ Sobre la falta de respuesta peninsular a la insatisfacción americana, véase Michael P. Costeloe, La respuesta a la Independencia. La España imperial y las revoluciones hispanoamericanas, 1810-1840 (México: Fondo de Cultura Económica, 2010), y Suárez de la Torre, Creación de estados. Sobre el impacto de esta polémica, véanse de Verónica Zárate Toscano, "Juan López Cancelada. Vida y obra" (tesis de maestría en Historia, Universidad Nacional Autónoma de México, México, 1986), y “La cuestión americana”. 
Juan López Cancelada: un escritor público entre dos mundos

López Cancelada llegó a Cádiz los primeros días de junio de 1810 luego de ser expulsado de Nueva España por orden del virrey y arzobispo Francisco Javier de Lizana y Beaumont (1809-1810). ${ }^{12}$ Este periodista vivió en Nueva España más de veinte años y fue el redactor de la Gazeta de México desde el año de 1805 hasta el de $1809 .{ }^{13}$ Sus conocimientos comerciales y periodísticos lo llevaron a ser la pluma elegida por el Consulado de México, que financió su trabajo en Cádiz. Desde su arribo a esta ciudad española, profundizó su mirada crítica sobre la ociosidad y la incapacidad americanas. En palabras de Zárate Toscano: "López Cancelada conservó lo que hemos llamado 'la obsesión americana' [...] Desde un principio había denunciado a los que bautizó como 'los criollos de la farsa', que eran autores de todos los males que había sufrido América". ${ }^{14}$

Su labor periodística en Cádiz se plasmó en varios escritos fundacionales de la polémica sobre la construcción de soberanía política americana. El primero de estos escritos se tituló Clamores de los europeos que viven en América a sus paisanos de España (1811). Este breve opúsculo se dirigió al "pueblo español" para reivindicar el honor de los paisanos españoles, quienes se sacrificaron por vivir y producir en la Nueva España y que nada tienen que ver con la crisis insurgente iniciada desde el año de 1808: "[A] dvertid que es una intriga el quereos persuadir que porque los rebeldes cabezas se llaman Hidalgo, Allende, Aldama, Abasolo, \&c., han nacido en las provincias de Nueva España: es una impostura: son hijos de los Europeos, nacidos el Hidalgo en la provincia de Michoacán, y los otros en la Guanajuato: los conozco personalmente, y me conocen a mí". ${ }^{15} \mathrm{El}$ periodista se

12 "Los clamores de estos infelices [los novohispanos] lograron que la [Junta] Central diese una providencia feliz, y fue la de nombrar Virrey de México a su arzobispo D. Francisco Xavier Lizana y Beaumont, que tomó las riendas del gobierno en agosto de 1809, diez meses después que los togados despotizaban bajo el nombre de Garibay." Fray Servando Teresa de Mier, Historia de la revolución de la Nueva España antiguamente Anáhuac o verdadero origen y causas de ella con la relación de sus progresos hasta el presente año de 1813, coord. de André Saint-Lu y Marie-Cécile Bénassy-Berling et al. (París: Publications de La Sorbonne, 1990), libro viII, 221.

13 Gabriel Torres Puga, "La transformación de la Gazeta de México, 1805-1808”, en Guerra, política y cultura en las independencias hispanoamericanas, ed. Marco Antonio Landavazo y Moisés Guzmán Pérez, Serie Encuentros 15 (Morelia: Universidad Michoacana de San Nicolás de Hidalgo; Guadalajara: El Colegio de Jalisco, 2013).

${ }^{14}$ Zárate Toscano, "Juan López Cancelada", 49-50.

15 Juan López Cancelada, Clamores de los europeos que viven en América a sus paisanos de España (Cádiz: Imprenta de Quintana, 1811), 2. Énfasis del autor. 
colocó como intermediario entre los dirigentes insurgentes y las imposturas o inflexiones ficticias del discurso que proponen. A su vez, le advirtió al pueblo español sobre los riesgos económicos de perder esas tierras tan ricas: "os suplico que seáis más cautos: si los Europeos son vencidos, perdisteis la Nueva España para siempre [...]". ${ }^{16}$

Las intrigas de los malos criollos (es así como Cancelada nomina a los insurgentes), en anuencia con la corrupción de ciertos funcionarios burocráticos, llevaron a la ruina moral y económica de los compatriotas peninsulares que habitaban Nueva España y que sostenían la economía de este espacio americano. El tono amenazante de Cancelada, tendiente a concientizar al lector español y alentarlo a tomar medidas defensivas frente a los ciudadanos peligrosos, se amplió de forma desmedida en su opúsculo posterior dirigido a las Cortes de Cádiz como informe de la situación insurgente en Nueva España: La verdad sabida y buena fe guardada. Origen de la espantosa revolución de Nueva España comenzada en 15 de septiembre de 1810. Defensa de su fidelidad (1811). En este escrito, López Cancelada profundizó la perspectiva denigrante sobre cierta porción del sector criollo, lectura de la realidad novohispana ya prefigurada en el informe del Consulado de México leído en las Cortes en sesión secreta en septiembre de 1811.

Este documento, a su vez, le permitió a Cancelada construirse en testigo de vista con una experiencia y saber privilegiados sobre las virtudes y defectos de una Nueva España consumida por la insurgencia. Su autoridad discursiva desestimó las observaciones del estudio Ensayo político sobre el reino de Nueva España del barón A. de Humboldt (1811) y la mirada contemplativa de Blanco-White sobre las quejas de los americanos (1811-1813):

[...] sus conexiones nunca podían ser tan extensas e íntimas con el pueblo como las mías. Yo había sido comerciante, labrador, minero, \&c., había tenido varias comisiones de los virreyes, entre ellas la de prender a los franceses en tiempo de su revolución, y examinar las correspondencias con los españoles, y en ninguna de estas averiguaciones hallé el más mínimo indicio de libertad e independencia, tan familiarizada en aquellos tiempos. Así pues, si el Barón de Humboldt oyó esa expresión a alguna persona del reino de México, no prueba que estuviese el pueblo imbuido de esas ideas, como injustamente supone El Español [...]. ${ }^{17}$

${ }^{16}$ López Cancelada, Clamores de los europeos, 3.

17 Juan López Cancelada, La verdad sabida y buena fe guardada: origen de la espantosa revolución de Nueva España comenzada en 15 de setiembre de 1810. Defensa de su fidelidad. Cuaderno primero... (México: Documentos publicados en la Gazeta de México, 1811), XI. 
La táctica argumentativa que desplegó a lo largo de todo este informe coincidió con sus declaraciones previas y consistió en una técnica de desmalezamiento de la "mala cosecha criolla" dentro del fiel y leal vasallaje americano. Es decir, López Cancelada hizo uso de su autoridad testimonial para caracterizar a la insurgencia novohispana como producto de unos pocos rebeldes y su accionar caótico: “i[Y] por qué ahora cuatro revoltosos hayan movido los ánimos de algunos buenos ciudadanos, ¿̇se ha de suponer que son efectos de una antigua deliberación?". ${ }^{18}$ Este procedimiento de caracterización de los criollos implicó en el relato de Cancelada describir a los habitantes de estos lares (y con ellos a todos los americanos) como seres similares a los niños o, en su defecto, a los animales.

En paralelo a la ridiculización del accionar criollo, López Cancelada hizo un uso estratégico de la prensa gaditana en un periódico que parodió el discurso del patriotismo criollo y mostró así la inconsistencia de la construcción cultural y política. Su periódico El Telégrafo Americano (18111812) se presenta como continuación de El Telégrafo de Guadalajara de Severo Maldonado: “[E]ste periódico contendrá lo que presenta otro de igual título en Guadalajara [...] un Americano que se separó del famoso cura Hidalgo de Dolores a la vista de su injusto procedimiento contra los Europeos residentes en Nueva España". ${ }^{19}$

El primer número del periódico de Cancelada construyó hábilmente la "máscara discursiva americana". En esta primera emisión, el periodista peninsular aunó la enunciación arrepentida del criollo Severo Maldonado con la defensa del informe del Consulado a manos de Francisco Gutiérrez de la Huerta, diputado por Burgos en las Cortes de Cádiz. En este número, Cancelada realizó una lectura apologética de los miembros españoles del Consulado de Nueva España, construidos como los buenos patriotas, mancillados por el mal manejo de la prensa como consecuencia de la apertura de la libertad de imprenta: "[...] lo que ahora con haber andado a la tienta en los papeles públicos, no nos queda más esperanza que la de saber que son capaces que sacrificar su misma existencia porque la Nueva España se mantenga unida a la Metrópoli”. ${ }^{20}$

Destacamos la apertura del periódico con el discurso del criollo arrepentido ya que en las últimas entregas de esta publicación (en especial los

${ }^{18}$ López Cancelada, La verdad sabida, XII.

19 Juan López-Cancelada, "Nota del editor", El Telégrafo Americano, n. 1 (10 de octubre 1811): 1 .

${ }^{20}$ López-Cancelada, "Nota del editor", 8. 
números 18, 19 y 20, respectivamente) se sellaría la genealogía infame criolla que Cancelada les adjudicó a los malos criollos que, según su opinión, eran recelosos, acaparaban las riquezas de las tierras y vivían como extranjeros en su propia patria. En el número 20 de este periódico, y manteniendo una trama narrativa, basada en anécdotas contadas por un testigo de vista de la realidad desigual novohispana, Cancelada busca desenmascarar el accionar tiránico de la figura del hacendado criollo sobre los campesinos. De esta forma, destaca dos escenas americanas en las que prevalece la crueldad del hacendado sobre los campesinos, tiranía que, en la perspectiva de este periodista español, avalaría las posteriores rebeliones de los americanos que buscaron liberarse de la opresión de estos estamentos. A continuación, citamos una de las escenas recreadas por Cancelada y tomadas como casos probatorios del atraso económico, político y cultural americanos:

¿A quién no se le traspasaría el corazón al ver en la provincia de Potosí (Puerto de la Cañada) cinco criaturas alrededor de una madre tan extenuada como ellas de hambre, abandonadas en medio de un páramo? La madre apenas me vio se puso de rodillas enseñándome un chico de pecho: los demás no podían tenerse en pie de flaqueza: me apeé inmediatamente, y de la provisión que llevaba para el camino comencé a repartirles pedazos de pan: ¿¿cuál sería el estado de necesidad cuando una de las criaturas como de cinco años no podía paladear? ¡Y cuál sería mi sorpresa al ver que otra menor apenas le pasó el estómago el primer bocado se quedó yerra! [...] y de qué provenía esta necesidad? De que el padre había huido de la justicia por una riña hacía tres días, y como no concurriese a la labor de la hacienda, pensando su dueño que lo hacia de malicia, negó la ración de maíz a la mujer. ¿Y a quién acudir a quejarse? El juez estaba a 50 leguas: este es otro motivo de ejercer a su salvo el hacendero su tiranía $[. ..]{ }^{21}$

Este diarista elige escenas de patetismo y desolación para denunciar el accionar de los criollos propietarios que deberían ejercer un rol de paternalismo económico y de ejemplo moral para con sus trabajadores mestizos, indios, criollos y mulatos. Su argumentación atravesada de dramatismo se sustenta en un testimonio de vista y de experiencia del narrador, quien presenta casos aislados que difícilmente puedan pensarse como ejemplos para justificar las problemáticas que vivían las distintas colonias americanas,

${ }^{21}$ Juan López Cancelada, “Adición a la nota segunda de la página 219 del número 18. Sobre el repartimiento de tierras”, El Telégrafo Americano, n. 20 (19 de febrero de 1812): 241-242. 
así como tampoco permiten comprender los motivos por los cuales distintos sectores de la población (sean urbanos, campesinos, criollos, mulatos, mestizos, indígenas, peninsulares) se juntaron para rebelarse contra un sistema de poder opresivo.

Ni vasallos, ni arrepentidos: americanos

Los ejemplos, casos y denuncias fabuladoras de Cancelada son desmentidas por los argumentos legales y jurídicos de Guridi Alcocer. En esta polémica se disputó el significado del concepto criollo como elemento guía de la decadencia americana. El procedimiento de Cancelada consistió en armar el número 18 de su periódico como una autobiografía con matices hagiográficos debido a las injusticias que tuvo que padecer para ser el portavoz sobre la vida en las Américas: "[...] tengo muchos enemigos: el haber emprendido con firmeza y resolución desengañar a la España de los errores en que querían imbuirla varios americanos para que no caminásemos con el debido acierto con respecto a las Américas, ha hecho desatar las furias infernales de algunos contra mí”. ${ }^{22}$ Para validar su sacrificio de buen patriota, Cancelada republicó una carta que un colaborador (nombrado El Europeo) escribió para el número 2226 del Diario de México (6 de noviembre de 1811). A continuación de la reivindicación pública de su persona, Cancelada publicó en el mismo número la advertencia que el Ayuntamiento novohispano le envió a la Regencia de España a causa de "la peligrosidad y posible fuga de la península del vil conspirador López Cancelada”. ${ }^{23}$ En esta advertencia, el Ayuntamiento novohispano les pedía a las autoridades españolas no dejarse seducir por el libelo La verdad sabida, que contenía "falsedades y calumnias [...] principalmente contra este Ayuntamiento”. ${ }^{24} \mathrm{~A}$ modo de refutación de las injurias sufridas, López Cancelada construyó al final del número 18, una fuerte crítica sobre la desigualdad económica que los criollos estipularon sobre las castas y la ruina en la que quedaron por alejarse de la Monarquía española: “¿Veis, Americanos, como, aunque al

${ }^{22}$ Juan López-Cancelada, “Advertencia”, El Telégrafo Americano, n. 18 (miércoles 5 de febrero de 1812): 209.

${ }^{23}$ Juan López Cancelada, "Representación hecha por el Ayuntamiento de México contra Cancelada-Es a la letra”, El Telégrafo Americano, n. 18 (5 de febrero de 1812): 214.

${ }^{24}$ López Cancelada, "Representación hecha por el Ayuntamiento": 214. 
principio se hizo declarar el odio contra los inculpables Europeos, venís, al fin, a ser vosotros los despojados de lo que ellos os dejaron?”. ${ }^{25}$

La escritura de Cancelada contribuyó a cimentar la representación de los criollos como hijos desagradecidos y abandonados por sus padres, así como también, y en venganza por sus aires de nobleza insatisfechos, en propietarios explotadores de sus empleados en el campo. Esta lectura tendenciosa fue refutada por Guridi Alcocer en el Censor Extraordinario en el año de $1812 .{ }^{26}$ Esta primera respuesta del diputado por Tlaxcala en las Cortes de Cádiz refutó los números 13 y 14 del periódico de Cancelada cuestionando la interpretación de este periodista. El artículo desestimó la lectura de Cancelada sobre la apropiación de ciertos criollos sobre los campos y la labor que en ellos se producía, accionar avalado por los derechos que las cédulas reales les otorgaban a los americanos. Guridi Alcocer realizó un trabajo minucioso de valoración de los documentos legales (Recopilación de Indias) a la hora de aplicarlos en América. A continuación, argumentó sobre la dura vida de los criollos para hacerse de un camino dentro de la burocracia en América debido a los favoritismos respecto de los españoles. Guridi refuta de este modo la lectura estadística de Cancelada sobre los empleos en América ocupados por criollos. Este diputado tlaxcalteca rescata las observaciones de ciertas autoridades ilustradas peninsulares que evidenciaron las fallas y distancias entre las leyes y su aplicación en los territorios americanos, y en especial señalaron el escaso reconocimiento político-institucional de los criollos (como fueron los casos de Solórzano, Ahumada, Macanaz y Feijoo):

¡Cuántos ejemplares de estos se habrán presentado a don Juan Cancelada en los 22 años que dice ha vivido en Nueva España! ¿No habrá visto la postergación que ven todos? Apelo al testimonio íntimo de su corazón, con que sólo recuerde las muchas provisiones y promociones hechas a sus ojos en todas las carreras en el largo tiempo de su residencia. Finalmente, Feijoo en su Teatro crítico (tomo 4 discurso 6) citando al doctor Castañeda habla de los estorbos "que tienen en aquellas regiones los sujetos para hacer fortuna por la carrera de las letras, de que se origina que los

25 Juan López Cancelada, ["Respuesta a la "Representación hecha por el Ayuntamiento de México...”], El Telégrafo Americano, n. 18 (5 de febrero 1812): 215-221. Énfasis del autor.

26 "Este número extraordinario se publicó como folleto en la Imprenta de Agapito Fernández Figueroa. Juan E. Hernández y Dávalos lo incluyó en su valiosa Colección de documentos para la historia de la guerra de Independencia de 1808 a 1821, t. III, comp. de José E. Hernández y Dávalos (México: José María de Sandoval, 1877-1882), doc. 151, 842-863, www. pim.unam.mx. Zárate Toscano, "Juan López Cancelada”, 81. 
más, o abandonándolas del todo, o tratándolas con menos cuidado, busquen la facultad de subsistir por otros rumbos". Podía citar otros autores; pero en obvio de la difusión, bastan los cuatro expresados, que son de nombre y todos europeos, para probar con autoridad la postergación de los americanos en los empleos. ${ }^{27}$

La crítica de Guridi Alcocer sobre Cancelada llevó a este último a redactar los números 18, 19 y 20. En estos números (en especial el 20) el periodista peninsular banalizó y mancilló la virtud del nombre criollos y estipuló una separación tajante entre los criollos de la América Septentrional y el uso del nombre americanos, propio de Estados Unidos:

El nombre de Americanos es el que se da allí a los de los Estados Unidos, y si se diera éste a los Criollos de nuestras Américas resultaba una confusión en las historias que están escritas, y hablan de Gachupines y Criollos sobre sucesos de América [...] como yo no se lo doy con el ánimo de satirizarlos, me es indiferente sustituirlo en Americanos. Hallo que todo el que nace en América es Americano, por consecuencia el Indio, Mulato, Negro, \&C., se iguala al blanco, y por eso la razón natural y convivencia ha sido la que desde luego ha fijado ese modo de distinguir unos de otros; y será siempre permanente en todos los naturales de allá $[\ldots]{ }^{28}$

La analogía de los motes criollos-americanos fue utilizada por Cancelada como un desplazamiento o ampliación que abarcó no sólo a los criollos blancos, sino a los indios y castas que poblaban Nueva España. Este proceder argumentativo reiteró la perspectiva degradada de sus dos escritos previos ya analizados. Al respecto, y para situar la polémica de Guridi Alcocer con Cancelada, debemos tener en cuenta el peso de la opinión pública, en particular en Cádiz y en Londres, como herramienta constructora de una ciudadanía política moderna que requería definir la identidad de los miembros de esta nueva nación política y visualizar (y excluir) a los miembros foráneos, forasteros, polizones o extranjeros. Esta redefinición de la pertenencia política-legal llevaría a un extenso debate en las Cortes de Cádiz y en la prensa periódica sobre quiénes pertenecían a la población hispánica (y con ello eran considerados ciudadanos políticos con su respectiva representación en las Cortes y en la Constitución gaditana); quiénes

${ }^{27}$ José Miguel Guridi Alcocer, “Contestación de D. José Miguel Guridi Alcocer al Telégrafo Americano. Censor Extraordinario (1812)”, en Colección de documentos, t. III, doc. 151, 11-12, www.pim.unam.mx.

28 Juan López Cancelada, "Por qué se llaman criollos los hijos de europeos nacidos en América”, El Telégrafo Americano, n. 20 (19 de febrero 1812): 246. 
eran concebidos como miembros de la sociedad sin poseer derechos civiles o políticos (como fue el caso de las castas según las propuestas de la Constitución gaditana) y, finalmente, qué ciudadanos políticos deberían ser denunciados como polizones o extranjeros por su comportamiento inmoral y corrupto que atentaba contra el sistema liberal que impulsaba y respaldaba la Constitución gaditana.

Fueron fundamentales los debates sobre la preocupante falta de representación de las castas americanas, restricción que implicó una desigualdad representativa para los reinos americanos y, con ello, la aceptación de una regulación política injusta. Sin embargo, nos interesa en esta sección trabajar con el tercer aspecto mencionado que implicó la denigración del otro, ya sea gachupín o criollo, por considerarlo un "mal ciudadano". Esta caracterización moral se concentró argumentalmente en el accionar corrupto y egoísta de cierto sector de la población que fue configurado como el contramodelo del proyecto de ciudadanía y república modernas. La connotación de ilegalidad y de invasión propia de la figura del polizón fue adjudicada a distintos sectores de la sociedad colonial novohispana de forma elástica y móvil según el enunciador y sus intereses.

La calidad de extranjería solía asociarse en los escritos de los criollos del siglo XVII y XVIII al desarraigo de los peninsulares por su escaso interés de permanencia en una sociedad que no concebían como propia a la que acudían con deseos de corta permanencia y largo rédito (de allí su carácter de advenedizos o recién llegados). Sin embargo, las polémicas letradas de la prensa periódica de Cádiz y Londres de los años 1811-1813 concibieron al ciudadano foráneo como el enemigo interior, el vecino que luchaba públicamente por la prosperidad de la nación, pero que, en su espacio íntimo, en su fuero interior, buscaba la forma de enriquecerse a través de la crisis política hispánica. Esta lectura construyó y reinterpretó la figura del polizón. ${ }^{29}$ Este término fue utilizado como herramienta de ataque tanto por los americanos que reivindicaban sus derechos ante las Cortes de Cádiz como por los peninsulares residentes en América que se vieron amenazados por las rebeliones y las propuestas de emancipación de ciertos sectores de las provincias americanas.

${ }^{29}$ En el Diccionario de autoridades: "Polizón. (Polizón) s. m. El sugeto ocioso y sin destíno, que anda de corrillo, en corrillo. Latín. Malè feriatus”. En Diccionario de la Real Academia Española: "1. m. y f. Persona que se embarca clandestinamente. 2. m. y f. Persona ociosa y sin destino, que anda de corrillo en corrillo". 
A modo de ejemplo de este particular uso, destacamos cuatro posturas que polemizaron sobre el mismo y lo concibieron como instrumento efectivo para proponer cambios y actualizaciones del sistema de legislación en el funcionamiento de la burocracia de la monarquía española en las provincias americanas. La primera acepción la encontramos en el número 12 del Redactor General del miércoles 26 de junio de 1811. Dentro de la sección "Variedades. América", se destaca una crítica sobre el error más grave del antiguo gobierno de España, que consistió en "enviar a América aquellas personas, que degradaban [a] sus familias en Europa con sus vicios. De aquí ha resultado necesariamente llenarse aquellos países de malvados, que se atraían el odio de los criollos, y deshonraban escandalosamente su patria". ${ }^{30}$ Esta es una lectura criollista que predominaba en las denuncias y reivindicaciones culturales y económicas realizadas por el criollismo conventual ${ }^{31}$ del siglo XVII y la posterior epistemología patriótica criolla del siglo XVIII. ${ }^{32}$

Paralelamente, en el mismo artículo publicado en el periódico gaditano, se plantea el peligro de ciertos hábiles peninsulares que se distanciaron del vociferante sector violento e ignorante peninsular:

Además de esta especie de hombres, pasaban a América otros, no menos perjudiciales, que prófugos muchas veces por delitos, o vagabundos al menos, se ocultaban

30 [Pedro Ponce], "Variedades. América”, El Redactor General, n. 12 (miércoles 26 de junio de 1811): 41.

${ }^{31}$ El sintagma de "criollismo conventual” es utilizado por Bernard Lavallé en su estudio Las promesas ambiguas. Ensayos sobre el criollismo colonial en los Andes (Lima: Pontificia Universidad Católica del Perú, Instituto Riva-Agüero, 1993), 159, y lo aplica a la contienda liderada por los frailes criollos dentro del sistema restringido de puestos jerárquicos dentro de la Iglesia en América.

${ }^{32}$ Cañizares-Esguerra entiende este concepto como "un discurso eclesiástico y aristócrata ligado a un conocimiento histórico en que las fuentes se juzgaban de acuerdo con una escala móvil de credibilidad, la cual, a su vez, estaba vinculada a jerarquías raciales y sociales [...] De acuerdo con esta peculiar perspectiva, los defectos historiográficos del pasado se atribuían al uso inadecuado que se hizo de buenas fuentes amerindias. Los epistemólogos patriotas argumentaron que las primeras historias se habían basado en el testimonio erróneo de plebeyos amerindios coloniales o en relatos confiables de los nobles amerindios precolombinos o de principios de la Colonia pero que fueron malinterpretados. Distinguir entre el testimonio de informantes amerindios de clase alta y el de los plebeyos era fundamental para la nueva historiografía hispanoamericana”. Jorge Cañizares-Esguerra, Cómo escribir la historia del Nuevo Mundo. Historiografías, epistemologías e identidades en el mundo del Atlántico del siglo XVIII, traducción de Susana Moreno Parada revisada por Jorge Cañizares-Esguerra (México: Fondo de Cultura Económica, 2007), 24-25. 
en los buques, y aparecían en aquellas regiones. Las leyes españolas de Indias, código digno de Solón, han adoptado para ellos el nombre francés de polizón, y previenen que a su arribo sean aplicados a las armas [...] este sabio reglamento no se cumple [...] De estos advenedizos sin educación ni moral, unos pasan el tiempo en las tabernas, dispuestos a cualquier infamia; otros más ambiciosos se introducen tierra adentro con alguna pacotilla, y suelen parar en ricos comerciantes, que a veces es obra de un solo día, mediante algún ventajoso casamiento. Tales son los principios y el origen de una gran parte de los habitantes de la América española, sin que por eso falten en ella muchos descendientes de los primeros conquistadores y oriundos de las más ilustres familias de la península; $y$, sin embargo, de esta clase abyecta se eligen regularmente los concejales de los ayuntamientos de América. ${ }^{33}$

Más allá de que este artículo satirizó el accionar de Cancelada, ${ }^{34}$ se concentró en hacer visible la negligencia de los funcionarios burocráticos en América, que aceptaron la permanencia y el enriquecimiento de estos hombres en estos lares.

Esta perspectiva fue refutada en el número 20 de El Telégrafo Americano del día 19 de febrero de 1812, número en el que Cancelada trabaja en profundidad la caracterización de los ociosos y desagradecidos criollos como hijos improductivos de los comerciantes peninsulares. El argumento de este periodista caracterizó la inutilidad de los hijos criollos como un accionar inmoral en tanto su omisión de responsabilidades cívicas implicó la obstrucción del progreso social. Según la versión de este escritor, el

${ }^{33}$ [Ponce, Pedro], "Variedades. América", El Redactor General, n. 12 (miércoles 26 de junio de 1811): 42.

${ }^{34}$ Desconocemos los medios con los que contó López Cancelada para arribar a Nueva España. Sabemos, gracias a las investigaciones de Zárate Toscano ("Juan López Cancelada”); Jesús Paniagua Pérez, “Introducción”, en Pedro Batista Pino-Juan López-Cancelada. Exposición suscinta y sencilla de la Provincia del Nuevo México y otros escritos, ed., introducción, notas, glosario e índices de Jesús Paniagua Pérez, Colección Tradición Clásica y Humanística en España e Hispanoamérica (León, España: Junta de Castilla; León, España: Universidad de León, 2007); Saint-Lu y Bénasy-Berling, coords., Historia de la revolución; Christopher Domínguez Michael, Vida de Fray Servando (México: Era, 2004), que este comerciante casó con una viuda española adinerada con la cual mantendría una relación problemática y de la cual se divorciaría a los pocos años. En este escrito y en la Historia de la revolución de Mier, caracterizan a Cancelada como un comerciante de poca monta, intruso en el mundo de las letras y sin capacidad para ser el vocero del Consulado de México y, mucho menos, el editor de la Gazeta de México, periódico de carácter oficialista a comienzos del siglo xix: "[...] la falta de estudios que confiesa en su Telégrafo Americano (sin que se necesitase telégrafo para saberlo) y la mala crianza que prueban sus desvergüenzas, groserías y dicharachos de verdulera, se puede inferir de su alcurnia, aunque él quiera entroncarla en condes y marqueses [...]" (Mier, Historia de la revolución, 15-16). 
sostén económico de los comerciantes peninsulares llevó con los años a conformar hijos criollos ociosos o hacendados viles que escapaban de las responsabilidades laborales. Por este motivo, Cancelada deseaba demostrar la peligrosidad de las revueltas americanas producto de la incapacidad de los malos criollos de concentrar y representar los intereses de todos los habitantes de América:

A la verdad, es demasiado buena la juventud americana a la vista del abandono en que se le ha dejado vivir por tantos años, y del último cevo [sic] que se le presentó. Es un milagro que haya criollo bueno, siendo así que hay muchísimos a toda prueba por su propia virtud. Es el mayor desconsuelo para el hombre reflexivo tener que hablar contra otros hombres inculpables de su conducta [...] Al verse abandonados, ultrajados, y reducidos de ricos a pobres, maldicen su existencia; la sangre española que circula por sus venas la miran como impedimento para poderse confundir entre los indios y las castas [...]. ${ }^{35}$

En este número Cancelada se ocupó del término polizón, que expurgó de todo sentido ligado a la delincuencia, para asociarlo a los jóvenes "que no llevan las licencias necesarias de la Corte [...] llevan en su lugar cartas de recomendación para sus tíos, parientes y paisanos de sus padres, o de los remitentes que los embarcan". ${ }^{36}$ Estos jóvenes de ascendencia montañesa y vizcaína se constituyeron en ciudadanos ejemplares debido a que se aplicaron a "la buena conducta que exige el giro del comercio", pero, como contracara, tuvieron hijos improductivos que se escaparon de sus responsabilidades. Destacamos la separación que realiza Cancelada en su argumentación entre la "buena - y productiva- conducta" peninsular frente a la conducta ociosa de los criollos americanos. De esta forma, este periodista desestimó la fuerte crítica que los diputados americanos y los publicistas criollos le hicieron al informe del Consulado de México de 1811 al que caracterizaron como documento escrito por comerciantes ignorantes de las problemáticas sociales americanas.

Es interesante observar cómo Cancelada trastocó el discurso criollista sobre la inmoralidad del comercio para dotarlo de una ética ciudadana que llevó a considerar a los polizones como ciudadanos ejemplares que sostienen

35 Juan López-Cancelada, "Principales motivos de ese odio y rivalidad entre gachupines y criollos”, El Telégrafo Americano, n. 20 (19 de febrero de 1812): 253-254.

${ }^{36}$ López-Cancelada, "Polizones en América. Contestación al Redactor n. 12”, El Telégrafo Americano, n. 20 (19 de febrero de 1812): 255-256. 
los espacios de sociabilidad urbanos: "[A] estos polizoncitos se deben las grandes obras y útiles establecimientos que vemos en la Nueva España [...] son los que fabricaron aquellos hermosos edificios, calzadas, paseos y todo lo que blasonan la hermosa México, y las demás ciudades y pueblos fundados por ellos". ${ }^{37}$ Es en la prensa y los debates políticos en donde los letrados se sintieron a gusto para verter sus insultos más corrosivos y sus imprecaciones más procaces sobre el enemigo político.

En respuesta a este número (y su suplemento), tanto Guridi Alcocer como Servando Teresa de Mier elaboraron sus respuestas polémicas esgrimiendo una biografía infame del escritor peninsular que significó para ellos la estampa de la ambición y la crueldad de los españoles en América. De esta forma, tanto el número del Censor General del viernes 1 de mayo de 1812, escrito por Guridi Alcocer, como la primera "Carta de un americano a El Español sobre su número XIX publicada en Londres el 11 de noviembre de 1811" y la Historia de la revolución de Nueva España (1813) de Mier coincidieron en denigrar la metodología vulgar de Cancelada y su perspectiva trastocada de los hechos históricos. Para ello, ambos letrados novohispanos recurrieron a una enunciación en tercera persona ligada a la versión de un testigo americano, estrategia para hacer más creíbles sus dichos. Este informante otorgaba detalles precisos de la conducta indigna de Cancelada en América. A su vez, Mier y Guridi se apropiaron del mote de americanos para reivindicar la fuerza política que contenía este nombre y dignificar el sentido moral del cual había sido despojado por la retórica vacía y animalesca de Cancelada: “[L]o que me parece es que ha contestado de la misma manera que ha dicho misa cuando ha pronunciado esta voz, y que su triunfo es semejante al del loro que rompiéndole una pierna de palo gritaba victoria, victoria, porque sabía articular esa palabra y no sabía, como se deja entender, lo que se decía". ${ }^{38} \mathrm{Al}$ respecto, Mier sostiene:

Por ahí viene Cancelada diarista pagado de los europeos de México con su cartilla entregada gratis a los 1300 soldados que los de Cádiz enviaron contra México el día 13 de noviembre y en ella les dice: "Los indios son los naturales del país: todos los demás no tienen otro derecho a él que el que les dieron nuestros antepasados conquistadores que es igual al que tenemos los españoles: ni puede probar otra cosa

${ }^{37}$ López-Cancelada, "Polizones en América. Contestación al Redactor n. 12”, El Telégrafo Americano, n. 20 (19 de febrero de 1812): 257.

38 José Miguel Guridi Alcocer, “Ampliación a la contestación de Cancelada”, Censor General (1 de mayo de 1812): 13. 
ningún americano: por lo que el indio es acreedor a nuestra consideración” [...] ¿Con qué si los criollos tienen el derecho que les dieron sus padres los conquistadores, los demás españoles que no son sus hijos tienen el mismo derecho que éstos por la fraternidad de Adán y Eva? [...] Lástima es que a Napoleón no le haya ocurrido la lógica de Cancelada, porque tenía justificada la guerra de España con sólo dejar peleando en ella a los polacos e italianos. ${ }^{39}$

No hubo sino algunos horterillas, como llaman en España, o caxerillos, como le dicen en México, o polizones, esto es, hombres bajos y ruines, como los nombran las leyes de Indias, salidos por contrabando de entre las heces de España, y que por lo mismo con un engreimiento cómico hacen en América muy de señores, conforme al refrán vanidad y pobreza es de una pieza $[. ..] .{ }^{40}$

\section{Conclusión}

Nos detuvimos en distintas modulaciones, usos y significaciones de los términos América/americanos. Estos conceptos actuaron como prisma de sentido en la guerra verbal del proceso de construcción de soberanía novohispana. Desde este foco, tanto diputados como publicistas y letrados (americanos españoles y españoles) desplegaron, articularon y fundamentaron un vocabulario político producto de la actualización de términos propios del Antiguo Régimen, como fueron el de patria, vasallaje y fidelidad. Así, los nuevos vínculos políticos configuran nuevas alianzas no ligadas preferentemente a órganos o corporaciones, como fue la familia en el Antiguo Régimen, sino que se conciben como conexiones trasatlánticas entre ciudadanos que establecen vínculos de paridad horizontal y ya no de obediencia piramidal (como lo era la relación del vasallo hacia su rey).

Las innovaciones en los vínculos letrados permiten valorar la apertura de la comunicación que se ha dado gracias al cambio de funciones de la opinión pública. La emancipación se plantea ahora como una guerra de palabras en la que cada contrincante deberá esgrimir su mejor espada o argumento verbal resignificando así términos familiares del Antiguo Régimen. Cada texto o intervención será considerada un acto político que deberá ser com-

${ }^{39}$ Fray Servando Teresa de Mier, "Primera carta de Un Americano [1811]", en Cartas de un americano 1811-1812, ed. de Manuel Calvillo (México: Secretaría de Educación Pública, 1987): 106.

${ }^{40}$ Fray Servando de Mier, Historia de la revolución, 96. 
prendido bajo determinadas condiciones semánticas de producción y que posee una intencionalidad determinada. ${ }^{41}$ Observamos y profundizamos la fuerza semántica que tuvieron los conceptos de América/americanos en la construcción de locus de enunciación de letrados tanto americanos como peninsulares que buscaron educar y movilizar a sus lectores.

Si tenemos en cuenta que se parte de una situación teórica en la que los contendientes son los unos españoles y los otros españoles con derechos disminuidos (los americanos), la independencia exige la precisión de una diferenciación de identidades que es lo que lleva a los americanos descendientes de españoles a identificarse formalmente con los americanos originarios y criticar la conquista. A partir de la escisión de la identidad entre peninsulares y americanos queda el largo camino de las identidades y proyectos locales, tanto en España como en América. A su vez, la guerra y la resignificación de palabras o conceptos tradicionales visibiliza el "desliz de la ciudadanía"42 que generaron los sucesos acaecidos en 1808 y que unieron el ejercicio de la ciudadanía a la apertura política vehiculizada por la opinión pública. A través de este desliz y apertura de la soberanía política, los letrados y publicistas novohispanos recurren a los términos América/americanos como máscaras discursivas para plantear las grietas y fallas tanto del sistema colonial en crisis como de las propuestas liberales y constitucionales de las Cortes gaditanas y proponer salidas alternativas a estos sistemas jurídico-legales peninsulares.

${ }^{41}$ Alejandra Pasino, "Los escritos de Manuel J. Quintana y José M. Blanco White en el Semanario Patriótico (1808-1810); sus aportes a la construcción del lenguaje del primer liberalismo español", Anuario del Centro de Estudios Históricos "Prof. Carlos S. A. Segreti", año 10, n. 10 (2010): 345.

${ }^{42}$ El sintagma del "desliz de la ciudadanía” lo elabora y trabaja Antonio Annino en su artículo “¿Ciudadanos o vecinos?”, en Ciudadanía política y formación de las naciones. Perspectivas históricas de América Latina, coord. de Hilda Sábato (México: Fondo de Cultura Económica, 1999), 66. Más allá de las restricciones y de las reconfiguraciones que sobre el concepto del ciudadano se hacen en los artículos 5 y 18 de la Constitución de Cádiz (en los que se excluye a las castas de la posibilidad de elección y de la calidad de ciudadanos), la revolución de 1808 ha habilitado la apertura de un sistema político inédito en España y sus territorios ultramarinos. La mutación cultural y política que se produce en 1808 en la Monarquía española y sus colonias no se genera de una maduración endógena, sino que ha sido impuesta por circunstancias exteriores y, en gran parte, inesperadas, que constituyen una de las paradojas más importantes del mundo hispánico. 


\section{Fuentes}

[Blanco White, José María]. "Real Orden publicada en Sevilla en la Gazeta del Gobierno del lunes 5 de junio de 1809, Decreto de 22 de enero de 1809." El Español, v. I, n. VI (30 de septiembre de 1810): 454-456.

[Blanco White, José María]. "Representación de la diputación americana a las Cortes de Cádiz.” El Español, v. IV, n. XxiII (30 de marzo de 1812): 370-389.

"Decreto v, 15 de octubre de 1810." En Colección de los decretos y órdenes que han expedido las Cortes Generales y Extraordinarias desde su instalación en 24 de septiembre de 1810 hasta igual fecha de 1811. T. 1. Cádiz, Imprenta Real, 1811, 10.

"Decreto Ix, 10 de noviembre de 1810. Libertad política de la imprenta." En Colección de los decretos y órdenes que han expedido las Cortes Generales y Extraordinarias desde su instalación en 24 de septiembre de 1810 hasta igual fecha de 1811. T. 1. Cádiz: Imprenta Real, 1811, 14-17.

"Informe del Real Tribunal del Consulado de México sobre la incapacidad de habitantes de Nueva España para nombrar representantes a las Cortes (27 de mayo de 1811)." En Colección de documentos para la historia de la guerra de Independencia de 1808 a 1821. T. I. Comp. de José E. Hernández Dávalos. México: José María de Sandoval, 1877-1882, doc. 224, www.pim.unam.mx.

Guridi Alcocer, José Miguel. "Contestación de D. José Miguel Guridi Alcocer al Telégrafo Americano. Censor Extraordinario (1812).” En Colección de documentos para la historia de la guerra de independencia de 1808 a 1821. T. III. Comp. de José E. Hernández y Dávalos. México: José María de Sandoval, 1877-1882, doc. 151, www.pim.unam.mx.

Guridi Alcocer, José Miguel. "Ampliación a la contestación de Cancelada. 1 de mayo 1812." Censor General. Colección de documentos para la historia de la guerra de Independencia de 1808 a 1821. T. III. Comp. de José E. Hernández y Dávalos. México: José María de Sandoval, 1877-1882, doc. 152, www.pim.unam.mx.

López Cancelada, Juan. Representación de Juan López Cancelada. México. Archivo Pares, América-México, Signatura: Estado, 57, E, n. 78, 1809, imagen 185-189, http://pares.mcu.es/GuerraIndependencia/catalog/show/2740053.

López Cancelada, Juan. La verdad sabida y buena fe guardada: origen de la espantosa revolución de Nueva España comenzada en 15 de setiembre de 1810. Defensa de su fidelidad. Cuaderno primero... México: Documentos publicados en la Gazeta de México, 1811.

López Cancelada, Juan. Clamores de los europeos que viven en América a sus paisanos de España. Cádiz: Imprenta de Quintana, 1811.

López Cancelada, Juan. "Nota del editor." El Telégrafo Americano, n. 1 (10 de octubre de 1811): 7-8. 
López Cancelada, Juan. "Advertencia." El Telégrafo Americano, n. 18 (5 de febrero de 1812): 209-213.

López Cancelada, Juan. ["Respuesta a la Representación hecha por el Ayuntamiento de México...".] El Telégrafo Americano, n. 18 (5 de febrero de 1812): 215-221. López Cancelada, Juan. "Representación hecha por el Ayuntamiento de México contra Cancelada-Es a la letra." El Telégrafo Americano, n. 18 (5 de febrero de 1812): 214.

López Cancelada, Juan. "Adición a la nota segunda de la página 219 del número 18. Sobre el repartimiento de tierras." El Telégrafo Americano, n. 20 (19 de febrero de 1812): 240-245.

López Cancelada, Juan. "Polizones en América. Contestación al Redactor n. 12." El Telégrafo Americano, n. 20 (19 de febrero de 1812): 255-259.

López Cancelada, Juan. "Por qué se llaman criollos los hijos de europeos nacidos en América." El Telégrafo Americano, n. 20 (19 de febrero de 1812): 246-255.

López Cancelada, Juan. "Principales motivos de ese odio y rivalidad entre gachupines y criollos." El Telégrafo Americano, n. 20 (19 de febrero de 1812): 253-254. [Maldonado, Francisco Servando.] "Discurso a todos los habitantes de América." El Telégrafo de Guadalaxara, t. I, n. 1 (27 de mayo de 1811): 3-8.

Mier, fray Servando Teresa de. "Manifiesto apologético [1810]." En Escritos inéditos. Introducción, notas y ordenación de textos de José María Miquel i Vergès y Hugo Díaz-Thomé, 39-168. México: El Colegio de México, Centro de Estudios Históricos, 1944.

Mier, fray Servando Teresa de. "Carta de Un Americano al Español sobre su número XIX [1811]." En Cartas de un americano, 1811-1812. La otra insurgencia. Ed. de Manuel Calvillo. Cien de México. México: Secretaría de Educación Pública, 1987.

Mier, fray Servando Teresa de. "Segunda carta de Un Americano al Español sobre su número XIX, contestación a su respuesta dada en el número xxiv [1812].” En Cartas de un americano 1811-1812. Ed. de Manuel Calvillo. Cien de México. México: Secretaría de Educación Pública, 1987.

Mier, fray Servando Teresa de. Historia de la revolución de la Nueva España antiguamente Anáhuac o verdadero origen y causas de ella con la relación de sus progresos hasta el presente año de 1813. Coord. de André Saint-Lu y Marie-Cécile Bénassy-Berling et al. París: Publications de La Sorbonne, 1990.

"Once proposiciones de los diputados americanos [1820-1821]." En Idea de una constitución. Escritos inéditos, de fray Servando Teresa de Mier. Introducción, notas y ordenación de textos de José María Miquel i Vergès y Hugo Díaz-Thomé. México: El Colegio de México, Centro de Estudios Históricos, 1944, 300-304.

[Ponce, Pedro]. "Variedades. América." El Redactor General, n. 12 (26 de junio de 1811): 41. 
Real decreto (14 de febrero de 1810). Biblioteca Virtual Luis Ángel Arango. Bogotá, Colombia, http://www.banrepcultural.org/blaavirtual/historia/palabras-que-nos-cambiaron/decreto/isla de-leon-febrero-14-1810.

Representación de la Diputación Americana a las Cortes de España (1 de agosto de 1811). En Colección de documentos para la historia de la guerra de Independencia de 1808 a 1821. T. III. Comp. de Juan E. Hernández y Dávalos. México: José María de Sandoval, 1877-1882, doc. 149, www.pim.unam.mx.

\section{Bibliografía secundaria}

Annino, Antonio. “¿Ciudadanos o vecinos?” En Ciudadanía política y formación de las naciones. Perspectivas históricas de América Latina. Coord. de Hilda Sábato. México: Fondo de Cultura Económica, 1999.

Ávila, Alfredo. En nombre de la nación. La formación del gobierno representativo en México (1808-1824). México: Taurus, 2002.

Ávila, Alfredo, y Rodrigo Moreno. "El vértigo revolucionario. Nueva España 18081821." Nuevo Topo. Revista de historia y pensamiento crítico (Buenos Aires), n. 5 (2008): 99-125. Republicado en dossier: Lo revolucionario en las revoluciones de independencia iberoamericanas. Historia Política (coord. de Marcela Ternavasio), n. 4 (2010): 1-36.

Breña, Roberto. "Pensamiento político e ideología en la emancipación americana. Fray Servando Teresa de Mier y la independencia absoluta de Nueva España." En Relatos de nación. La construcción de las identidades nacionales en el mundo hispánico. Ed. de Francisco Colom González, 73-102. Madrid: Iberoamericana; Frankfurt: Vervuert, 2005.

Cañizares-Esguerra, Jorge. Cómo escribir la historia del Nuevo Mundo. Historiografías, epistemologías e identidades en el mundo del Atlántico del siglo XVIII. Traducción de Susana Moreno Parada revisada por Jorge Cañizares-Esguerra. México: Fondo de Cultura Económica, 2007. Primera edición 2001.

Costeloe, Michael P. La respuesta a la Independencia. La España imperial y las revoluciones hispanoamericanas, 1810-1840. México: Fondo de Cultura Económica, 2010. Primera edición 1986.

Domínguez Michael, Christopher. Vida de Fray Servando. México: Era, 2005. Primera edición 2004.

Escamilla, Iván. "La élite letrada eclesiástica y la cultura de la controversia, primera mitad del siglo xviII." En Expresiones y estrategias. La Iglesia en el orden social novohispano. Coord. de María del Pilar Martínez López-Cano y Francisco Javier Cervantes Bello, 363-392. México: Universidad Nacional Autónoma de México, 
Instituto de Investigaciones Históricas; Puebla: Benemérita Universidad Autónoma de Puebla, Instituto de Ciencias Sociales y Humanidades "Alfonso Vélez Pliego", 2017.

Fernández Sebastián, Javier. "La crisis de 1808 y el advenimiento de un nuevo lenguaje político. ¿Una revolución conceptual?” En Las experiencias de 1808 en Iberoamérica. Comp. de Alfredo Ávila y Pedro Pérez-Herrero, 105-134. Alcalá: Universidad de Alcalá; México: Universidad Nacional Autónoma de México, 2008.

Guerra, François-Xavier. Modernidad e independencia: ensayos sobre las revoluciones hispánicas. Madrid: MAPFRE-América, 1992.

Herrejón Peredo, Carlos. "Hidalgo y la nación.” Relaciones, v. xxv, n. 99 (2004): 257-284.

Ibarra, Antonio. "Orden, desorden y atraso: el acertijo latinoamericano de la originaria inestabilidad política y el tormentoso cambio institucional, a propósito del Bicentenario." Revista Uruguaya de Historia Económica, año 1, n. 1 (2011): 103-110.

Iriarte López, Iñaki. “América-España.” En Diccionario político y social del mundo iberoamericano. Dir. de Javier Fernández Sebastián, ed. de la entrada "América-americanos” de Joao Feres Júnior, 116-129. Madrid: Fundación Carolina; Madrid: Sociedad Estatal de Conmemoraciones Culturales; Madrid: Centro de Estudios Políticos y Constitucionales, 2009.

Lavallé, Bernard. Las promesas ambiguas. Ensayos sobre el criollismo colonial en los Andes. Lima: Pontificia Universidad Católica del Perú, Instituto Riva-Agüero, 1993.

Landavazo, Marco Antonio. "Guerra, discurso y terror en la independencia de México." En Creación de estados de opinión en el proceso de independencia mexicano (1808-1823). Coord. de Laura Suárez de la Torre, 99-124. México: Instituto de Investigaciones Dr. José María Luis Mora, 2010.

Palti, Elías. El tiempo de la política. El siglo XIX reconsiderado. Buenos Aires: Siglo XXI Editores, 2007.

Paniagua Pérez, Jesús. “Introducción”. En Pedro Batista Pino-Juan López-Cancelada. Exposición suscinta y sencilla de la Provincia del Nuevo México y otros escritos. Ed., introducción, notas, glosario e índices de Jesús Paniagua Pérez, Colección Tradición Clásica y Humanística en España e Hispanoamérica. León, España: Junta de Castilla; León, España: Universidad de León, 2007.

Paniagua Pérez, Jesús. “Introducción”. En Juan López Cancelada, editor. El Telégrafo Americano (10 de octubre de 1811-31 de marzo de 1812). Ed., introducción, notas, glosario e índices de Jesús Paniagua Pérez. Facsímil de Cádiz: Imprenta de Manuel Santiago de Quintana, 1812. Colección Tradición Clásica y Humanís- 
tica en España e Hispanoamérica. León, España: Junta de Castilla y Universidad de León, 2008.

Pasino, Alejandra. "Los escritos de Manuel J. Quintana y José M. Blanco White en el Semanario Patriótico (1808-1810); sus aportes a la construcción del lenguaje del primer liberalismo español." Anuario del Centro de Estudios Históricos "Prof. Carlos S. A. Segreti", año 10, n. 10 (2010): 343-363.

Rojas, Rafael. La escritura de la Independencia. El surgimiento de la opinión pública en México. México: Taurus; México: Centro de Investigación y Docencia Económicas, 2003.

Súarez de la Torre, Laura. "El desdibujamiento de una madre, la pérdida de una hija. España y México (1818-1823).” En Creación de estados de opinión en el proceso de independencia mexicano (1808-1823). Coord. de Laura Suárez de la Torre. México: Instituto de Investigaciones Dr. José María Luis Mora, 2010.

Torres Puga, Gabriel. Opinión pública en Nueva España. Indicios de un silencio imposible (1767-1794). México: El Colegio de México, 2010.

Torres Puga, Gabriel. “La transformación de la Gazeta de México, 1805-1808.” En Guerra, política y cultura en las independencias hispanoamericanas. Ed. Marco Antonio Landavazo y Moisés Guzmán Pérez, Serie Encuentros 15. Morelia: Universidad Michoacana de San Nicolás de Hidalgo; Guadalajara: El Colegio de Jalisco, 2013.

White, Hayden. "Introducción: la poética de la historia." En Metahistoria. La imaginación histórica en la Europa del siglo XIX, 13-51. México: Fondo de Cultura Económica, 1992.

Zárate Toscano, Verónica. “Juan López Cancelada. Vida y obra." Tesis inédita de la maestría en Historia, Universidad Nacional Autónoma de México, México, 1986.

Zárate Toscano, Verónica. "La cuestión americana en Juan López Cancelada.” En Insurgencia y republicanismo. Coord. de Jesús Raúl Navarro García, 67-86. Sevilla: Consejo Superior de Investigaciones Científicas, Escuela de Estudios Hispano-Americanos, 2006.

Zárate Toscano, Verónica. "Con la pólvora en el tintero. Juan López Cancelada y la independencia novohispana." En Creación de estados de opinión en el proceso de independencia mexicano (1808-1823). Coord. de Laura Suárez de la Torre, 195228. México: Instituto de Investigaciones Dr. José María Luis Mora, 2010.

Zermeño Padilla, Guillermo. "Los usos políticos de América/americanos (México 1750-1850)." Revista de Estudios Políticos, n. 134 (2006): 71-95.

Zermeño Padilla, Guillermo. "Apropiación del pasado, escritura de la historia y construcción de la nación en México." En La nación y su historia. Independencias, relato historiográfico y debates sobre la nación: América Latina, siglo XIX. Coord. de Guillermo Palacios, 81-112. México: El Colegio de México, 2009. 